\title{
Aproximaciones estéticas a las camas y cobijas fotografiadas por Yenny Banesa Bonilla
}

\author{
Aesthetic approaches to the beds and blankets photographed \\ by Yenny Banesa Bonilla Avendaño
}

\begin{abstract}
Abordagem estética às camas e cobertores fotografadas por Yenny Banesa Bonilla Avendaño
\end{abstract}

Jaime Ruiz Solórzano

Candidato a doctor en estudios sociales

Universidad Surcolombiana

jairuso@usco.edu.co

\section{Resumen}

El presente texto de reflexión tiene como propósito ofrecer una entrada a la comprensión a las camas y mantas elaboradas por los campesinos del municipio de Baraya, Huila, que indagó Yenny Banesa Bonilla como temática de las fotografías creadas como resultado de su proyecto de investigacióncreación. Estas imágenes fotográficas han servido para diseñar la carátula y las ilustraciones del presente número de la Revista Paidea Surcolombiana. Es necesario precisar que el abordaje estético se efectúa sobre los objetos creados por los campesinos, pero no sobre las fotografías en sí; ello con la intención de identificar la relevancia de la temática registrada. En este sentido se comenta la materialidad de las obras, su origen proveniente de las prácticas creativas populares, y sus conexiones con la Estética Pragmática (Schusterman, 2002), la Estética Relacional (Bourriaud, 2004) y la Estética Prosaica (Mandoky, 2006).

Palabras claves: Camas, cobijas, expresiones populares, estética pragmática, estética prosaica, estética relacional.

\begin{abstract}
The present text of reflection has as purpose to offer an entrance to the understanding to the beds and blankets elaborated by the farmers of the
\end{abstract}


Municipality of Baraya, Huila, that Yenny Banesa Bonilla investigated as a subject of the photographs created as a result of her research-creation project. These photographic images have served to design the cover and illustrations of the present issue of Paidea Surcolombiana Magazine. It is necessary to specify that the aesthetic approach is carried out on the objects created by the farmers, but not on the photographs themselves; this, with the intention of identifying the relevance of the registered theme. In this sense, the materiality of the works is commented, their origin proceeding from the popular creative practices, and their connections with the Pragmatic Aesthetics (Schusterman, 2002), the Relational Aesthetics (Bourriaud, 2004) and the Prosaic Aesthetics (Mandoky, 2006).

Keywords: Beds, blankets, popular expressions, pragmatic aesthetics, prosaic aesthetics, relational aesthetics.

\section{Resumo}

Este documento de discussão se destina a fornecer um portal para compreender as camas e cobertores feitos pelos agricultores no município de Baraya, Huila, que Yenny Banesa Bonilla explorou como tema das fotografias criadas como resultado de seu projeto de criação de pesquisa. Estas imagens fotográficas serviram para desenhar a capa e ilustrações da presente edição da Revista Paidea Surcolombiana. É necessário especificar que a abordagem estética é realizada nos objetos criados pelos camponeses, mas não nas próprias fotografias; isso com a intenção de identificar a relevância do tema registrado. Neste sentido, é comentada a materialidade das obras, sua origem advém das práticas criativas populares, e suas conexões com a Estética Pragmática (Schusterman, 2002), a Estética Relacional (Bourriaud, 2004) e a Estética Prosaica (Mandoky, 2006).

Palavras - chave: Camas, cobertores, expressões populares, Estética Pragmática, Estética Prosaica, Estética Relacional.

La investigación-creación de Yenny Banesa Bonilla es significativa, en la medida que efectúa una propuesta fotográfica basada en una temática poco indagada, como son las estéticas que se encuentran en las áreas rurales de nuestro país $y$, específicamente, en el Departamento del Huila. Es en las casas de los campesinos del municipio de Baraya donde ella comienza a encontrar las diversas maneras como los habitantes resuelven el mobiliario para dormir y las mantas con las cuales se abrigan.

A nivel material las camas halladas son adaptaciones en metal y piezas de madera, talladas con herramientas básicas; encontró además soluciones sorprendentes para la estabilidad 
de las camas, como el uso de ladrillos en los soportes y el alargamiento de patas laterales para adaptarlas a los desniveles de los pisos. Mientras los tendidos son colchas hechas con retazos, mantas tejidas, compradas e intervenidas.

Las soluciones formales de las camas nos hablan de un mundo duro, donde la función se encuentra por encima del embellecimiento; no obstante trazas de éste se encuentran en las sensibilidades que recurren a la talla tosca, al enlucido de la madera con tintes, al uso de esmaltes industriales para los metales; y en las cobijas al abigarramiento del color, la mixtura de fibras, la diversidad en las técnicas del tejido. De acuerdo con los materiales empleados, se percibe que las camas y las mantas fueron elaboradas con la intención de asegurar su duración.

Tanto las camas como los tendidos son factibles de inscribir dentro de las prácticas artísticas de los estratos sociales populares, teniendo en cuenta que son expresiones "de lo diferente, desde los haceres de sectores que reimaginan sus situaciones diversas y recrean las formas de su tradición propia" (Escobar, 2013. p. 281), aunadas a las representaciones dominantes difundidas por los medios. Es decir, se trata de tradiciones que pueden recoger las prácticas creativas ancestrales amalgamadas con las imaginerías rurales actuales, vigentes en los campos colombianos; advirtiendo que no se encuentran totalmente alejadas de las producciones masivas que se destinan a los pobladores rurales.

Podemos decir que la importancia cultural de este tipo de prácticas descritas, puede comprenderse dentro del resignificación de las expresiones populares; además, teniendo en cuenta el "revival" suscitado como oposición ante la homogenización cultural que pretende imponer el Neoliberalismo. Tal validez se encuentra en que las expresiones populares buscan reconocer la vigencia de los microrrelatos, la reivindicación de la identidad y la resistencia a la hegemonía cultural.

A nivel estético se podrían relacionar con la categoría de lo "rústico", que evidencia "la vida en el campo, las costumbres de los campesinos, su manera de pensar y de sentir...que expresa los sólidos valores del arraigamiento, a veces del silencio o del secreto. Lo rústico contiene un elemento de autenticidad" (Souriau et alt, 1998. p. 977). En este sentido, las camas y sus cobijas son creaciones auténticas de una comunidad rural con limitados accesos a las oportunidades de formación educativa y cultural. Por lo cual los campesinos crean sin ninguna pretensión o conciencia de que lo laborado pueda pertenecer a algún canon artístico o estético.

De aquí que, estas prácticas creativas constituyen labores correspondientes a las necesidades 
sentidas, propias de una "situación desventajosa de ciertos sectores marginados de una participación social plena, pero, a partir de esta definición negativa de lo popular en cuanto excluido" (Escobar, 2013. p. 281). Es decir, que es en las mismas exigencias de la existencia donde se forjan las prácticas, las formas y las poéticas que resuelven necesidades básicas, como el descanso o el abrigo; al tiempo, que se pone en común sensibilidades propias, generalmente ignoradas.

Tal ignorancia probablemente es debida a que los encargados de teorizar el arte se centran casi que exclusivamente en las producciones urbanas, mientras otros se preocupan de las expresiones producidas por las minorías. Por lo cual, se dificulta "reconocer los significados multicapa, multívocos y matizados del arte popular, porque le es indiferente desde el principio y no quieren prestar a estas obras la atención simpatética necesaria para desenredar esas complejidades. Pero a veces simplemente no entienden de que se habla" (Schusterman, 2002. p. 249). En nuestro país aún falta indagar las prácticas creativas y las estéticas de sociedades y colectivos marginados; en esta situación la Licenciatura en Educación Artística ha efectuado algunas iniciativas, tendientes a

${ }^{1}$ Katia Mandoky explica que la estesis es "la sensibilidad o condición de abertura o permeabilidad del sujeto al contexto en que está inmerso...estesis como abertura del consolidar paulatinamente su abordaje.

Lo que pone en evidencia la investigación-creación de Yenny Banesa Bonilla es una forma de arte que podemos relacionar con la Estética Pragmatista, enunciada por Richard Schusterman; quien explica el origen y fuerza de las expresiones de la cultura popular por su ligamen necesario con el mundo de la vida, totalmente alternas a las prácticas propias de lo que se denomina el "mundo del arte", sustentado por sus máquinas de formación, creación, difusión y consumo.

Podemos decir que las camas y las mantas de los campesinos del municipio de Baraya también corresponderían a lo que Katya Mandoky denomina como Estética prosaica, por fuera de los límites del Arte y las artesanías, definida como "la teoría de las sensibilidades sociales y del papel de la estesis en las estrategias de constitución e intercambio de identidades individuales $y$ colectivas" (2006. p.16); es decir, que la estética prosaica es "la estética $^{1}$ en lo cotidiano... (incorporada a) intercambios sociales concretos" (Ibíd., p. 11-12).

De aquí que las camas y las cobijas de los campesinos del municipio de Baraya se encuentran por fuera de los marcos que exige el arte canonizado; signado por la

sujeto en tanto expuesto a la vida" (2006 :1112). 
autonomía formal, la originalidad innovadora, la creación única, el aval institucional, cuando se trata de creación inscritas en los "relatos maestros" o los "formalismos" del arte moderno; o en la capacidad de generar teorizaciones y reflexividad por encima de la solución visual, si se ubica en el arte contemporáneo.

Por el contrario, las camas y las cobijas son como una especie de antítesis, se trata de labores desinteresadas de la cualificación formal o estilística, inveteradas, reiterativas, anónimas, con funciones específicas; correlacionadas con los materiales disponibles, las exigencias climáticas del territorio, y el modo de vivir en las áreas rurales.

Estas prácticas creativas, sin ser presupuestada por los campesinos, implican una auténtica Estética relacional (Bourriaud, 2004), en la medida que contribuyen a ocupar de manera creativa el tiempo, a resolver necesidades sentidas, a propiciar el bienestar familiar, a ambientar de la mejor manera posible los lugares de habitación; además, siendo comunes durante la existencia cotidiana de los habitantes del ámbito territorial enunciado. Es decir, la estética relacional a la que aludimos se origina entre los habitantes de las casas campesinas y los visitantes, siendo mediadas por la percepción, la manipulación y el uso de los objetos creados; donde se ponen en escena los afectos, las capacidades comunicativas y las sensibilidades de los campesinos del municipio de Baraya.

\section{Referencias}

Bourriaud, Nicolas (2004). Estética relacional. Buenos Aires: Adriana Hidalgo.

Escobar, Ticio (2013). Estética de las artes populares. Cuestiones sobre el arte popular. En Xirau, Ramón y Sobrevilla, David. Estética.

Enciclopedia Iberoamericana de Filosofía. Madrid: Trota.

Mandoki, Katya (2006). Prácticas estéticas e identidades sociales.

Prosaica Dos. México: Siglo veintiuno-CONACULTAFONCA.

Souriau, Étienne, et alt (1998).

Diccionario Akal de estética. Madrid: Akal.

Schusterman, Richard (2002), Estética pragmatista. Viviendo la belleza, repensando el arte. Barcelona: Idea Books. 